\title{
MATURAÇÃO DO QUEIJO MINAS ARTESANAL DA MICRORREGIÃO CAMPO DAS VERTENTES E OS EFEITOS DOS PERÍODOS SECO E CHUVOSO
}

\section{Ripening of artisanal Minas cheese from the "Campo das Vertentes" region and the effects of dry and wet periods}

\author{
Luiz Carlos Gonçalves Costa Júnior. ${ }^{1 *}$, Victor José Moreno ${ }^{2}$, \\ Fernando Antonio Resplande Magalhães ${ }^{l}$, Renata Golin Bueno Costa ${ }^{I}$, \\ Eliane Campos Resende ${ }^{l}$, Karla Beatriz Almeida Carvalho ${ }^{l}$
}

\section{RESUMO}

Existe no Brasil expressiva produção de queijos artesanais fabricados a partir de leite cru, e dentro deste contexto, Minas Gerais tem destaque nessa atividade com suas cinco microrregiões reconhecidas oficialmente. Dentro destas, a do Campo das Vertentes foi a última a ter reconhecimento. Avaliar o efeito dos períodos seco e chuvoso durante a maturação de queijos Minas artesanais (QMA) da microrregião supracitada foi o principal objetivo deste estudo, que também relacionou aspectos da composição físico-química dos 10 aos 30 dias de maturação. Foram selecionadas quatro queijarias cadastradas e que atenderam às exigências legais e de boas práticas para comporem o experimento. As análises do teor de umidade, umidade na massa desengordurada do queijo (UMDQ) e $\mathrm{pH}$ demonstraram que estes valores variaram muito entre os queijos e foram mais elevados no período seco. Índices de extensão e profundidade da proteólise comportaram-se com variação entre as amostras e avançaram no período de maturação, porém, foram maiores no período chuvoso. Mesmo sabendo que a umidade dos queijos exerce forte influência na proteólise, assim como outros fatores tais como doses de coagulante e pingo, a temperatura ambiente observada nos dois períodos da maturação também foi muito importante para o avanço da proteólise.

Palavras-chave: proteólise; fermento endógeno; queijo artesanal; pingo; leite cru.

1 Empresa de Pesquisa Agropecuária de Minas Gerais, Instituto de Laticínios Cândido Tostes (EPAMIG/ ILCT), Rua Tenente de Freitas, 116, Santa Terezinha, 36560-000, Juiz de Fora, MG, Brasil. E-mail: luiz.carlos@epamig.br.

2 Instituto Federal de Ciência e Tecnologia Goiano, Campus Urutaí, GO, Brasil.

* Autor para correspondência. 


\begin{abstract}
There is an expressive artisanal cheeses production in Brazil, manufactured from raw milk, and within this context, the state of Minas Gerais has a highlight in this activity with its five micro regions officially recognized. Within these, "Campo das Vertentes" was the last to have recognition. Evaluating the effect of dry and wet periods during the ripening of artisanal Minas cheese of the micro region above mentioned was the main objective of this study, which also related aspects of physicochemical composition of 10 to 30 days of ripening. Four registered dairies were selected and who attended legal requirements and good manufacturing practice to compose the experiment. The analysis of moisture content, moisture to the non fat substance (MNFS) and $\mathrm{pH}$ showed that these values varied greatly among cheeses and were highest in the dry season. Indexes of proteolysis behaved with variation between samples and advanced in the period of ripening, however, they were higher in the wet season. Even aware that the moisture content of the cheeses exerts strong influence on proteolysis, as well as other factors such as dosage of coagulant and "drop", the room temperature observed in two periods of ripening was also very important for the advancement of proteolysis.
\end{abstract}

Keywords: proteolysis; endogenous starter; artisanal cheese; “drop”; raw milk.

\section{INTRODUÇÃO}

Existe no Brasil uma expressiva produção de queijos artesanais fabricados a partir de leite cru, cujos processos produtivos tradicionalmente têm sido passados de geração em geração. Constituem a forma de subsistência de inúmeras famílias no meio rural, além da bagagem cultural das regiões produtoras.

A produção de queijos artesanais diferencia-se da industrial pelo fato de não usarem processos mecanizados de produção e pasteurização do leite, e por ter a obrigatoriedade do emprego do pingo. Esse se caracteriza pelo soro-fermento salgado e coletado da fabricação anterior para uso na fabricação do dia (IMA, 2011).

No Brasil, os queijos artesanais estão caracterizados por regiões produtoras e embora o Estado de Minas Gerais como um todo tenha vocação para a produção, atualmente existem cinco microrregiões reconhecidas e oficializadas como produtoras do queijo Minas artesanal (QMA): Serro,
Serra da Canastra, Cerrado (antigo Alto Paranaíba), Araxá e Campo das Vertentes (EMATER-MG, 2011).

A microrregião Campo das Vertentes (MCV), embora tenha tradição secular na produção de queijos, foi reconhecida oficialmente somente em 2009. Ocupa uma área de $6.254 \mathrm{~km}^{2}$, com participação dos seguintes municípios: Barroso, Conceição da Barra de Minas, Coronel Xavier Chaves, Carrancas, Lagoa Dourada, Madre de Deus de Minas, Nazareno, Prados, Piedade do Rio Grande, Resende Costa, Ritápolis, Santa Cruz de Minas, São João Del Rei, São Tiago e Tiradentes (IMA, 2009; EMATER-MG, 2012).

Com a inclusão da microrregião Campo das Vertentes, muitos produtores que vivem da atividade puderam se adequar à legislação pertinente. Outros novos produtores também tiveram a oportunidade de se inserir de forma a atender às leis, e assim obterem suas produções e instalações regularizadas.

Neste novo contexto, percebe-se que a forma de padronizar a produção da microrregião, assim como todas as características de 
composição dos queijos, ainda carece de muita contribuição dos órgãos de pesquisa, sanitários e de inspeção. Também necessita do apoio governamental para que a produção possa atingir os patamares de outras microrregiões do Estado de MG, que já se encontram mais organizadas, com associações de produtores. As microrregiões do Serro e Canastra estão pleiteando até a denominação de origem controlada, como acontece de forma crescente na Europa com produtos desta natureza.

A maturação é um processo importante para melhoria das características dos queijos. É a última fase da fabricação, podendo variar de semanas a até mais de dois anos, dependendo do queijo produzido. Durante esse período, sob a ação de enzimas lipolíticas e proteolíticas, uma série de fatores de ordem biológica, química e bioquímicas acontece numa sucessão complexa. A maturação modifica as propriedades químicas e físicas da massa do queijo, influencia na textura e consistência e forma compostos que serão responsáveis pelo desenvolvimento do flavor característico de cada variedade (FOX; McSWEENEY, 1998).

Dos três principais eventos bioquímicos na maturação de queijos, a proteólise é o mais complexo e em maior grau de importância. É a principal responsável pela passagem de uma textura dura e de consistência "borrachenta" na coalhada fresca a um corpo de massa flexível, liso, macio e sabor característico de um queijo curado (FOX; McSWEENEY, 1998).

A maior parcela de proteólise se deve à ação do coalho na maioria das variedades de queijo, sendo que a degradação das caseínas se deve às proteases (ou proteinases) microbianas residuais, provenientes do fermento, e de proteínas nativas do leite como a plasmina (ALAIS, 2003; FOX; McSWEENEY, 1998). No decurso destas reações, peptídeos hidrofóbicos podem ser produzidos, levando ao gosto amargo, que resultam em rejeito por parte dos consumidores. No entanto, numa concentração adequada e balanceada com outros compostos, estes peptídeos amargos podem contribuir de forma positiva com o flavor do queijo (FOX; McSWEENEY, 1998.).

O acompanhamento da maturação em queijos artesanais também se faz importante e necessário, pois o QMA embora seja muitas vezes consumido fresco, tradicionalmente é fabricado para ser consumido maturado. Ainda não se tem uma definição legal do período de maturação pelo qual esses queijos devam cumprir, porém, já se permite que queijos artesanais tradicionalmente elaborados a partir de leite cru sejam maturados por um período inferior a sessenta dias (BRASIL, 2013).

Adefinição de novo período de maturação será realizada após a avaliação dos estudos pelo órgão estadual e/ou municipal de inspeção industrial e sanitária reconhecidos pelo Sistema Brasileiro de Inspeção de Produtos de Origem Animal - SISBI/POA. Esta liberdade de maturação inferior a sessenta dias fica restrita a queijaria situada em região de indicação geográfica registrada ou tradicionalmente reconhecida e em propriedade certificada (BRASIL, 2013).

Os conceitos extensão e profundidade surgiram para expressar as mudanças que ocorrem durante a proteólise de queijos na maturação. A extensão quantifica ou mensura os peptídeos solúveis de alta massa molecular, produto da ação proteolítica das enzimas do coalho sobre as caseínas, liberados para a fase aquosa do queijo. É considerado um fator indicativo da proteólise primária (WOLFSCHOON-POMBO; LIMA, 1989; $\mathrm{BECH}, 1993)$.

O índice de profundidade, por sua vez, quantifica ou mensura a formação de substâncias de baixa massa molecular, como aminoácidos, oligopeptídeos e aminas acumuladas durante o período de maturação. Essas substâncias são produto da ação proteolítica das enzimas microbianas sobre compostos nitrogenados oriundos da degradação primária das caseínas (WOLFSCHOON-POMBO; LIMA, 1989). 
Avaliar o efeito dos períodos seco e chuvoso durante a maturação de queijos Minas artesanais (QMA) da microrregião supracitada foi o principal objetivo deste estudo, que também relacionou aspectos da composição físico-química dos 10 aos 30 dias de maturação

\section{MATERIAL E MÉTODOS}

\section{Amostragem}

Inicialmente realizou-se uma busca de produtores credenciados ou em fase de credenciamento, aptos a produzirem o QMA na MCV conforme legislação pertinente e documentação do Instituto Mineiro de Agropecuária (IMA). Embora diversos produtores de QMA fossem localizados para atender aos pré-requisitos do projeto, foram selecionados somente os que atenderam às exigências de serem cadastrados no IMA. Sendo assim, quatro propriedades foram selecionadas para participarem do experimento, com a concordância de seus proprietários.

\section{Coleta e preparo das amostras}

Para cada uma das quatro queijarias foram coletados três lotes distintos de queijos (repetições) que foram maturados nas propriedades e analisados após 10, 20 e 30 dias de maturação nos dois períodos seco e chuvoso.

Os queijos coletados foram embalados em sacos plásticos de PVC transparente, acondicionados em caixa isotérmica, contendo gelo reciclável de forma a mantê-los sob temperatura de refrigeração, evitando assim, variações abruptas do local até o laboratório de análises no Instituto de Laticínios Cândido Tostes da EPAMIG, em Juiz de Fora, MG.

Os dados climatológicos foram solicitados ao Instituto Nacional de Meteorologia (INMET). Foram fornecidos os dados de precipitação diária $(\mathrm{mm})$, temperaturas máximas, mínimas e médias diárias $\left({ }^{\circ} \mathrm{C}\right)$. Os dados compreenderam os períodos seco e chuvoso com abrangência nos intervalos onde se deram as coletas amostrais.

\section{Análises físico-químicas}

Os teores percentuais $(\mathrm{m} / \mathrm{m})$ de Sólidos Totais foram analisados pelo método gravimétrico em estufa a $102{ }^{\circ} \mathrm{C} \pm 2{ }^{\circ} \mathrm{C}$ (BRASIL, 2006); teores percentuais $(\mathrm{m} / \mathrm{m})$ de gordura pelo método butirométrico Van Gulik (BRASIL, 2006). O teor percentual $(\mathrm{m} / \mathrm{m})$ de umidade na massa desengordurada do queijo (UMDQ) foi determinado pela relação: UMDQ $=[\%$ UMIDADE $/ 100-\%$ GORDURA $]$ x 100. Para a determinação de $\mathrm{pH}$ dos queijos utilizou-se o medidor de $\mathrm{pH}$ digital de bancada da marca Qualxtron, modelo 8010 (BRASIL, 2006). Os teores percentuais $(\mathrm{m} / \mathrm{m}) \mathrm{de}$ Nitrogênio total, Nitrogênio solúvel em $\mathrm{pH}$ 4,6 e Nitrogênio solúvel em TCA a $12 \%(\mathrm{~m} / \mathrm{v})$ foram determinados pelo método Kjeldahl modificado (PEREIRA et al., 2001) para se calcular índices de: extensão de proteólise (relação \% de NSpH4,6/NT); e profundidade de proteólise (relação \% de NSTCA 12\%/NT).

\section{Delineamento experimental}

Foi conduzido um delineamento experimental com três fatores ou tratamentos qualitativos, sendo eles: queijarias com quatro níveis (1, 2, 3 e 4); períodos (efeito da sazonalidade) com dois níveis (seco e chuvoso) e tempo de maturação com três níveis $(10,20$ e 30 dias após secagem dos queijos). Desses 24 tratamentos e 3 repetições, resultaram 72 unidades experimentais.

Foi adotado o delineamento em blocos casualizados, com parcelas subdivididas conforme arranjo estatístico ilustrado na Figura 1.

\section{Análises estatísticas}

Os dados gerados das variáveis respostas foram tabulados em planilha eletrônica 
utilizando-se o Software Microsoft Excel 2010 e transcritos para o Software "Sistema para Análises Estatísticas" - SAEG, da Universidade Federal de Viçosa - MG (RIBEIRO JUNIOR; MELO, 2008).

Foram verificados: normalidade como pressuposto ao uso da estatística paramétrica por meio do teste de Lilliefors; teste F de Snedecor para verificar a homocedastidade entre as variâncias dos tratamentos; e teste de Tukey para avaliar as diferenças estatísticas existentes entre as médias dos tratamentos de fator qualitativo (queijarias). Para o fator período do ano, o teste F é conclusivo, uma vez que este apresenta apenas dois níveis: análise de correlação de Pearson para fatores de nível quantitativo e nível de significância $(\mathrm{p}<0,05)$.

\section{RESULTADOS E DISCUSSÃO}

A análise de variância indicou que o teor de umidade dos queijos apresentou resultados estatisticamente diferentes entre queijarias, períodos seco e chuvoso e tempo de maturação $(\mathrm{p}<0,05)$.

A Tabela 1 apresenta os resultados de teor de umidade geral do experimento, teores médios dos períodos seco e chuvoso e suas respectivas variações.

O maior teor médio de umidade dos queijos no período seco é justificado pela tecnologia de produção adotada nas queijarias de forma a compensar a baixa umidade relativa do ar naquele período, pois é sabido que os queijos maturam-se à temperatura ambiente, tendendo à maior desidratação. Essa prática se resume em deixar os queijos com maior teor de umidade por meio do aumento no tamanho dos grãos, na quebra da massa, e/ou diminuindo ainda a pressão manual durante a enformagem dos queijos.

Pôde-se notar também uma falta de padronização mais acentuada no período seco em relação ao teor de umidade dos queijos, face aos elevados desvios padrão e maior coeficiente de variação, considerado alto.

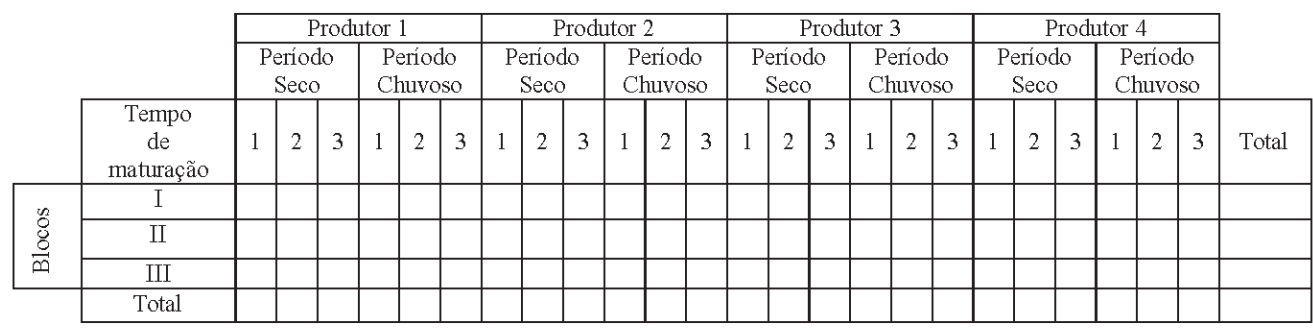

Figura 1 - Delineamento em blocos casualizados com parcelas subdivididas

Tabela 1 - Média percentual de umidade $(\mathrm{m} / \mathrm{m})$ dos queijos Minas artesanais (QMA) da microrregião do Campo das Vertentes (MCV) nos períodos seco e chuvoso, com seus respectivos desvios padrão (DP) e coeficiente de variação (CV)

\begin{tabular}{lccccc} 
& \multicolumn{2}{c}{ Média \pm DP } & \multicolumn{2}{c}{ Período seco } & \multicolumn{2}{c}{ Período chuvoso } \\
\cline { 2 - 5 } Umidade & $35,84 \pm 7,78$ & Média \pm DP & CV \% & Média \pm DP & CV \% \\
\cline { 2 - 5 }$\%(\mathrm{~m} / \mathrm{m})$ & & $39,00 \pm 10,27$ & 26,3 & $32,60 \pm 2,89$ & 8,8 \\
\hline
\end{tabular}

Médias seguidas pela mesma letra, na linha, não diferem significativamente entre si pelo teste $\mathrm{F}(\mathrm{p}<0,05)$. 
Os resultados indicam que, no período seco, os queijos podem ser classificados tanto de baixa como média umidade segundo regulamento técnico de identidade e qualidade (RTIQ) de queijos brasileiros (BRASIL, 2006). Já no período chuvoso, a tendência de classificação desses queijos é serem de baixa umidade $(<36 \%)$.

Oliveira (2010), avaliando a umidade em 32 amostras do QMA na MCV, encontrou teor médio de $58,3 \%(\mathrm{~m} / \mathrm{m})$ com $\pm 4,12 \%$. Porém, somente em queijos recém fabricados, que tendem a apresentar teor mais alto de umidade, e ainda sem mencionar a época de fabricação desses queijos, que também influencia significativamente nos produtos. Altos percentuais de umidade dos queijos também favorecem as reações e o avanço da proteólise, porém, outros fatores também contribuem para o processo.

Costa Júnior et al. (2009) encontraram na microrregião da Canastra teores médios de umidade de queijos Minas artesanais mais elevados no período seco $(52,0 \% \mathrm{~m} / \mathrm{m})$ contra $38,8 \%(\mathrm{~m} / \mathrm{m})$ no chuvoso, em estudo com condições semelhantes de coleta de dados e ao longo da maturação.

As curvas da Figura 2 ilustram o com- portamento do teor de umidade dos QMA da MCV durante a maturação, nos períodos seco e chuvoso.

Percebe-se que, embora as médias de umidade dos queijos os diferenciem nos períodos seco e chuvoso $(\mathrm{p}<0,05)$, ao término dos 30 dias de maturação, encontram-se muito próximas $(29,22 \% \mathrm{~m} / \mathrm{m}$ no período seco e $28,33 \% \mathrm{~m} / \mathrm{m}$ no chuvoso). As curvas permitem estimar o teor de umidade dentro do intervalo dos 20 dias de maturação (de 10 a 30 dias). Ao final da maturação, em ambos os períodos seco e chuvoso, o QMA já se classifica como de baixa umidade, ou seja, abaixo de $36,0 \%(\mathrm{~m} / \mathrm{m})$ conforme RTIQ (BRASIL, 2006).

Os resultados da análise de variância para a variável UMDQ indicam que, exceto as interações dupla tempo de maturação $x$ queijaria e a tripla tempo de maturação $\mathrm{x}$ período $\mathrm{x}$ queijaria, todas as outras fontes de variação apresentaram-se significativas $(\mathrm{p}<$ $0,01)$, o que denota grande heterogeneidade desta variável.

Assim como no teor de umidade, a UMDQ apresentou teor médio mais elevado no período seco $(57,72 \% \mathrm{~m} / \mathrm{m})$ contra $49,45 \% \mathrm{~m} / \mathrm{m}$ no período chuvoso. Esta variável, segundo

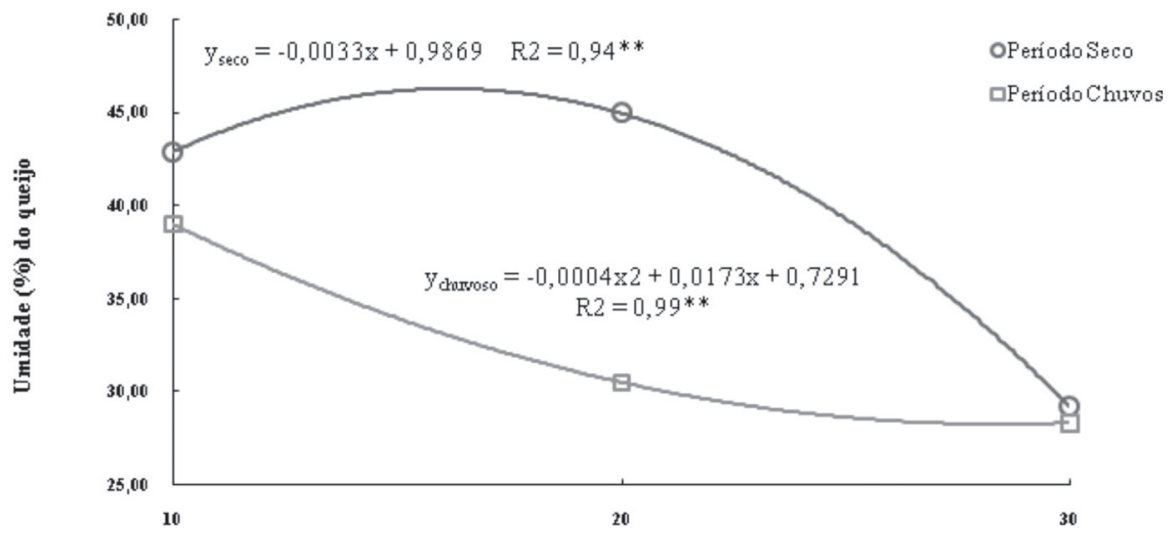

Figura 2 - Curvas ajustadas para teor de umidade do QMA da MCV ao longo de 30 dias de maturação, nos períodos seco e chuvoso 
Fox et al. (2000), deve apresentar intervalo entre $50-57 \%(\mathrm{~m} / \mathrm{m})$ para não comprometer o desenvolvimento normal na maturação.

As curvas da Figura 3 ilustram o comportamento do teor de UMDQ dos QMA da MCV durante a maturação, nos períodos seco e chuvoso.

No caso da UMDQ, em ambos os períodos o teor médio encontra-se elevado (acima de $57 \% \mathrm{~m} / \mathrm{m}$ ) aos 10 dias da maturação e foi diminuindo conforme o avanço do tempo. Aos 30 dias de maturação, a UMDQ atingiu média de $46,01 \%$ e $44,37 \%(\mathrm{~m} / \mathrm{m})$, respectivamente, para seco e chuvoso. Esses valores iniciais elevados (acima de $57 \% \mathrm{~m} / \mathrm{m}$ ) podem ter comprometido a "qualidade" do processo de maturação dos queijos, principalmente nos queijos produzidos no período seco, que demoram mais a atingir o valor crítico citado, ou seja, somente ao final da maturação.

Para os índices de proteólise, a análise de variância indica que para a extensão, exceto $\mathrm{a}$ interação tempo de maturação $\mathrm{x}$ período do ano, todas as outras fontes de variação se mostraram significativas $(\mathrm{p}<0,01$ a $\mathrm{p}<0,05)$. Para a profundidade, todas as fontes de variação se mostraram significativas $(\mathrm{p}<0,01$ a $\mathrm{p}<0,05)$. Estes dados denotam grande heterogeneidade destes dois aspectos físicoquímicos.
Tanto na extensão quanto na profundidade, os queijos do período chuvoso apresentaram índices médios mais elevados (extensão 13,2\% e profundidade 8,0\%), quando comparados ao período seco (extensão $10,8 \%$ e profundidade $5,9 \%$ ).

Embora os dados médios indiquem maiores extensão e profundidade no período chuvoso $(p<0,01)$, foi possível perceber a heterogeneidade de comportamento destas variáveis, que apresentaram diferenças grandes entre os períodos seco e chuvoso e mesmo entre as próprias queijarias. Porém, em nenhum momento percebeu-se maiores índices no período seco que no chuvoso, seja entre produtores ou nos tempos de maturação avaliados, como ilustrado na Figura 4, que trazem as curvas da extensão e profundidade dos QMA da MCV.

A extensão de maturação medida pela relação percentual do $\mathrm{NSpH} 4,6 / \mathrm{NT}$ é exercida na sua maior parte por influência do coalho, e que neste caso não houve dosagens diferenciadas por parte dos produtores do QMA nos períodos estudados. Embora o teor de umidade dos queijos exerça uma grande influência para o avanço proteolítico, o que aconteceu de forma superior no período seco, ainda assim a extensão apresentou um avanço maior desde o início do período

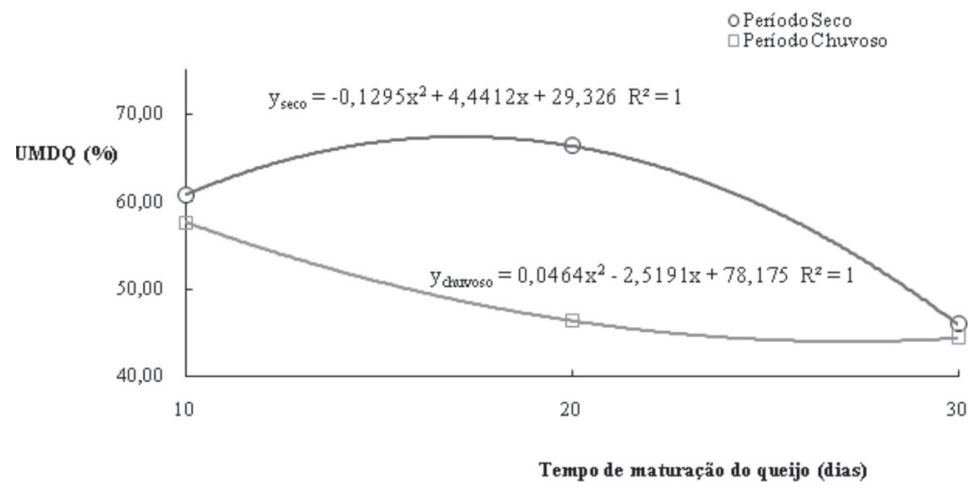

Figura 3 - Curvas ajustadas para teor de UMDQ do QMA da MCV ao longo de 30 dias de maturação nos períodos seco e chuvoso 
chuvoso. Isso pode ser explicado, talvez, pela forte influência da temperatura ambiente mais elevada nesse período, pois o QMA é maturado à temperatura ambiente. No período chuvoso, as mínimas situaram-se em torno de $20^{\circ} \mathrm{C}$ atingindo $30,9^{\circ} \mathrm{C}$ de pico, e com média em torno de $25^{\circ} \mathrm{C}$. No período seco, as mínimas não passaram dos $10^{\circ} \mathrm{C}$, e a máxima de $28,9^{\circ} \mathrm{C}$ só se verificou no final da maturação da $2^{\mathrm{a}}$ repetição, com médias de $18^{\circ} \mathrm{C}$. Estas variações de temperatura ambiente podem ter influenciado mais na proteólise dos queijos do que na sua composição, como a umidade e UMDQ.

Para a profundidade de maturação, mensurada pela relação percentual $\mathrm{NS}_{\mathrm{TCA} 12 \%} / \mathrm{NT}$, essa é mais influenciada pelo fermento. No caso dos QMA, o fermento, também chamado de pingo, se usado em maior volume e acidez numa fabricação pode resultar em índice de profundidade de proteólise mais elevado. Assim, é sabido que no período seco os produtores adicionam dosagens mais elevadas para compensar as baixas temperaturas, de forma a igualar a fermentação da massa. Esta adição de dose mais elevada no período seco parece não ter colaborado para maior avanço da profundidade, e sim as temperaturas mais elevadas do período chuvoso. Essas últimas colaboraram desde o início para índices de proteólise maiores durante todo processo, uma vez que os QMA são maturados sem quaisquer embalagens à temperatura ambiente.

A análise de variância indicou para a variável $\mathrm{pH}$ diferenças significativas $(\mathrm{p}<0,01)$ entre os períodos seco e chuvoso, tempo de maturação e queijarias. Não houve diferenças significativas nas interações períodos $\mathrm{x}$ queijarias e tripla $(\mathrm{p}>0,05)$.

As curvas da Figura 5 ilustram o comportamento do $\mathrm{pH}$ dos QMA da MCV ao longo da maturação nos períodos seco e chuvoso.

Percebe-se que desde o início da maturação o $\mathrm{pH}$ é mais elevado no período chuvoso, mesmo onde predominam temperaturas mais elevadas, o que deveria favorecer a fermentação da massa do queijo e resultar em menor valor de $\mathrm{pH}$. Neste caso, as doses de pingo mais elevadas no período seco podem ter favorecido o abaixamento do $\mathrm{pH}$, aliados aos maiores teores de sólidos totais dos QMA nesse período, que concentram mais lactose e esta é fermentada para produção de ácido lático que abaixa o $\mathrm{pH}$. Intervalos de $\mathrm{pH}$ entre 4,85 e 5,20 favorecem o avanço normal da maturação (FOX, et al., 2000), o que ocorreu desde o início nos dois períodos, seco e chuvoso, permanecendo até os 20 dias. À medida que avança a proteólise há um aumento dos valores de $\mathrm{pH}$ devido à for-
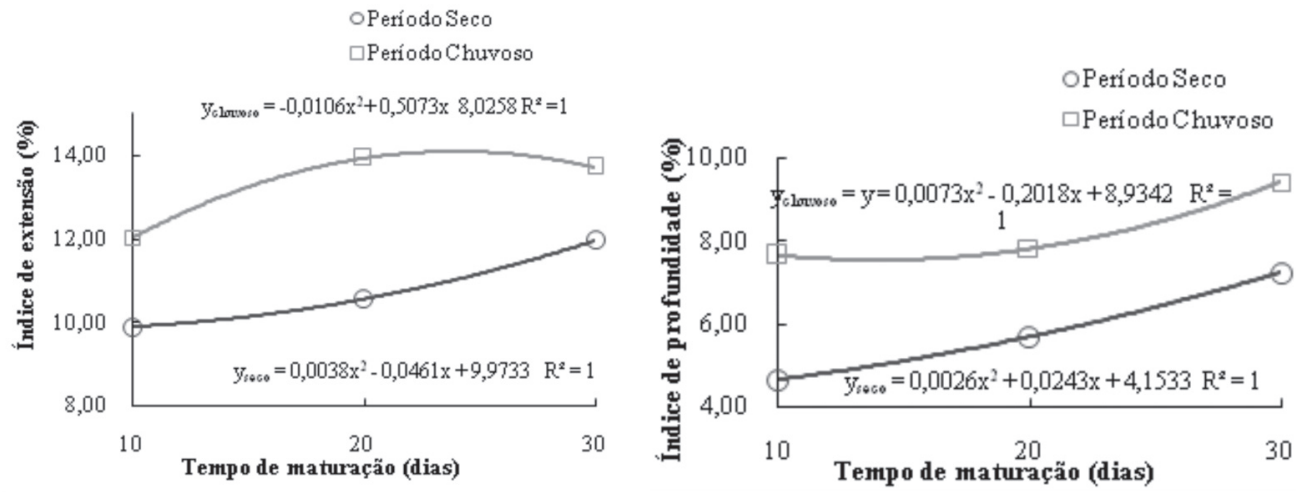

Figura 4 - Curvas ajustadas para os índices de extensão e profundidade de proteólise do QMA da MCV ao longo de 30 dias de maturação, nos períodos seco e chuvoso. 
mação de compostos nitrogenados alcalinos, produto da degradação proteica (FOX, 1989; UPADHYAY, et al., 2004), conforme o esperado.

\section{CONCLUSÕES}

As queijarias artesanais da MCV alteram suas tecnologias de fabricação nos períodos seco e chuvoso. Deixam o ponto do grão da coalhada mais úmido no período seco para suportar a menor umidade relativa do ar ao longo da maturação e tornar os queijos mais úmidos durante toda maturação.

A UMDQ é mais elevada no período seco, desde o início até final da maturação, do que no período chuvoso e atinge valores que podem comprometer a qualidade da proteólise dos queijos.

Os índices de proteólise são mais intensos no período chuvoso e podem sofrer maior influência da temperatura ambiente, mais elevada do que os fatores intrínsecos de composição como teor de umidade, $\mathrm{pH}$ e UMDQ.

$\mathrm{O} \mathrm{pH}$ dos QMA da MCV foi maior no período chuvoso, provavelmente devido à maior influência de menor dose de pingo empregada neste período do que propriamente da temperatura. Porém, esse procedimento não comprometeu a qualidade da proteólise no início deste período até 20 dias de maturação e, no caso do período seco, do início ao final.

\section{AGRADECIMENTOS}

A equipe agradece à FAPEMIG pelo financiamento da pesquisa (projeto $\mathrm{CVZ}$ APQ-01239-10) e concessão de bolsas à parte da equipe. À EPAMIG/ ILCT pelo apoio e contrapartida para realização da pesquisa; à equipe de apoio do ILCT e bolsistas pelo auxílio e boa vontade nas tarefas que contribuíram para o sucesso do projeto. Ao Mestrado Profissionalizante em Ciência e Tecnologia do Leite e Derivados, parceria UFJF/EPAMIG ILCT /EMBRAPA pela oportunidade de inserir o projeto no programa para duas dissertações, no qual este trabalho é parte de uma das dissertações. E, principalmente, aos produtores de QMA da $\mathrm{MCV}$, que abriram suas portas para a equipe,

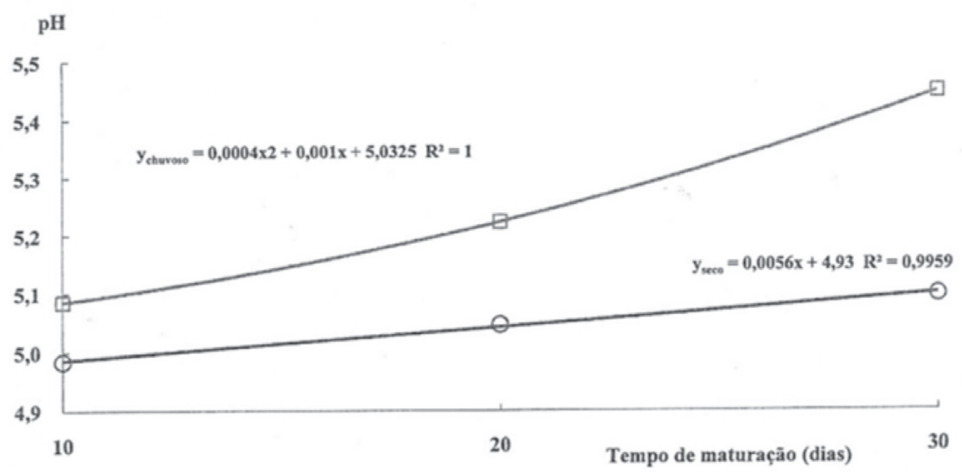

Figura 5 - Curvas ajustadas para pH dos QMA da MCV ao longo de 30 dias de maturação, nos períodos seco e chuvoso 
acreditaram no nosso trabalho que tem como meta melhorar as condições daquela e de outras regiões que atuam nessa atividade, de forma a contribuirmos para o seu desenvolvimento e com isso traga melhorias na qualidade de vida das famílias que dependem direta ou indiretamente dessa secular arte de fazer queijos: muito obrigado!!!

\section{REFERÊNCIAS}

ALAIS, C. Ciencia de la leche: principios de técnica lechera. Barcelona: Reverté, 2003. 4.ed $873 \mathrm{p}$.

$\mathrm{BECH}, \mathrm{A} . \mathrm{M}$. Characterizing ripening in UFcheese. International Dairy Journal, v. 3, n. 4-6, p. 329-342, 1993.

BRASIL. Ministério da Agricultura, Pecuária e Abastecimento. Instrução Normativa no ${ }^{-68}$, de 12 de dezembro de 2006. Oficializa os métodos analíticos oficiais físico-químicos, para controle de leite e produtos lácteos. Diário Oficial da República Federativa do Brasil, Brasília, 14 dez. 2006. Seção 1, p. 8.

BRASIL. Ministério de Estado da Agricultura, Pecuária e Abastecimento. Instrução Normativa $n^{\circ}$ 30, de 07 de agosto de 2013. Estabelece critérios adicionais para elaboração de queijos artesanais. Diário Oficial da República Federativa do Brasil, Brasília, 08 ago. 2013. Seção 3, p. 19.

COSTA JUNIOR, L. C. G. et al. Variações na composição de queijo Minas artesanal da Serra da Canastra nas quatro estações do ano. Revista do Instituto de Laticínios Cândido Tostes, v. 64, n. 371, p. 13-20, 2009.

EMATER-MG. Mapa do Queijo Minas Artesanal. Belo Horizonte, [2011]. Disponível em: <http:// www.emater.mg.gov.br/portal.cgi?flagweb $=$ site pgn_downloads_vert\&grupo $=135 \&$ menu $=59>$. Acesso em: 29 nov. 2012.

FOX, P. F. Proteolysis during cheese manufacture and ripening. Journal of Dairy Science, v. 72, n. 6, p. 1379-1400, 1989.
FOX, P. F. et al. Biochemistry of Cheese Ripening. In: $\quad$ Fundamentals of cheese science. Gaithersburg: Aspen Publication, 2000. cap. 11, p. 236-281.

FOX, P. F.; McSWEENEY, P. L. H. Chemistry and biochemistry of cheese and fermented milks. In: . Dairy chemistry and biochemistry. London: Blackie Academic \& Professional, 1998. cap. 10 , p. 403-418.

INSTITUTO MINEIRO DE AGROPECUÁRIA (IMA). Portaria $\mathbf{n}^{\mathbf{0}} \mathbf{1 0 2 2}$, de 03 de novembro de 2009. Identifica a microrregião do Campo das Vertentes. Belo Horizonte, 2009. Disponível em: <http://imanet.ima.mg.gov.br/nova/legis/ portarias_pdf/1022.pdf $>$. Acesso em: $18 \mathrm{dez} .2012$.

INSTITUTO MINEIRO DE AGROPECUÁRIA (IMA). Queijo Minas Artesanal. Belo Horizonte, [2011]. Disponível em: <http://www.ima.mg.gov.br/ certificacao/queijo-minas-artesanal-link $>$. Acesso em: 18 dez. 2012.

OLIVEIRA, V. J. Da qualidade e organização da produção ao reconhecimento de região produtora de queijo minas artesanal: análise da experiência dos produtores da região de São João Del Rei e seu entorno. 2010. 204 p. Tese (Doutorado em Ciência dos Alimentos) Universidade Federal de Lavras, Lavras, 2010.

PEREIRA, D. B. C. et al. Físico-química do leite e derivados: métodos analíticos. 2 ed. Juiz de Fora: Templo, 2001. 234p.

RIBEIRO JUNIOR. J. I.; MELO, A. L. P. de. Guia Prático para utilização do Sistema para Análises Estatísticas (SAEG). Viçosa: Folha, 2008. 288p.

UPADHYAY, V. K. et al. Proteolysis in cheese during ripening. In: FOX, P. F. et al. Cheese: chemistry, physics and microbiology. 3 ed. London: Elsevier. 2004. v. 1, p. 391-433.

WOLFSCHOON-POMBO, A. F., LIMA, A. Extensão e profundidade de proteólise em Queijo Minas Frescal. Revista do Instituto de Laticínios Cândido Tostes, v. 44, n. 261-266, p. 50-54, 1989. 